BMJ Open Sport \& Exercise Medicine

\section{Detailed injury epidemiology in contemporary dance: a 1-year prospective study of 134 students}

To cite: van Winden $D$, Van Rijn RM, Richardson A, et al. Detailed injury epidemiology in contemporary dance: a 1-year prospective study of 134 students. BMJ Open Sport \& Exercise Medicine 2019;0:e000453. doi:10.1136/ bmjsem-2018-000453

Accepted 17 January 2019 (c) Author(s) (or their employer(s)) 2019. Re-use permitted under CC BY-NC. No commercial re-use. See rights and permissions. Published by BMJ.

${ }^{1}$ Codarts University of the Arts, Rotterdam, The Netherlands ${ }^{2}$ Department of Human Movement Sciences, Amsterdam Movement Sciences, Vrije Universiteit Amsterdam, Amsterdam, The Netherlands ${ }^{3}$ Performing artist and Athlete Research Lab (PEARL), Rotterdam, The Netherlands ${ }^{4}$ Institute of Brain and Behavior, Amsterdam, The Netherlands ${ }^{5}$ Faculty of Sports and Nutrition, Amsterdam University of Applied Sciences, Amsterdam, The Netherlands

${ }^{6}$ Rotterdam Arts and Science Lab (RASL), Rotterdam, The Netherlands

Correspondence to Dr Rogier M Van Rijn; rmvanrijn@codarts.nl

\section{ABSTRACT}

Aim We investigated the extent and characteristics of injuries in contemporary dance students.

Methods During one academic year, 134 students of Bachelor dance and Bachelor dance teacher from Codarts University of the Arts (Rotterdam, the Netherlands) were prospectively monitored monthly, using the Performing Artist and Athlete Health Monitor which includes the Oslo Sports Trauma Research Centre Questionnaire on Health Problems.

Results 130 students were included in the analyses. The response rate of monthly completed questionnaires was $80 \%$. During the academic year, $97 \%$ of students reported at least one injury, mental complaint or other health problem. The 1-year injury incidence proportion was $81 \%$. Of these injured students, $58 \%$ were substantially injured (ie, problems leading to moderate or severe reductions in training volume or performance or complete inability to participate in activities). The monthly injury proportion (all injuries) ranged from $23 \%$ to $43 \%$ and for substantial injuries from $6 \%$ to $17 \%$. The injury incidence rate per 1000 hours dance exposure was $1.9(95 \% \mathrm{Cl} 1.7$ to 2.2$)$. Ankle/foot (30\%), lower back (17\%) and knee (15\%) were the most common sites of injury.

Conclusion Contemporary dance students are at high risk for injuries. Injury prevention programmes among contemporary dance students should focus on the ankle/ foot, lower back and knee.

\section{INTRODUCTION}

Contemporary dance students participate in long hours of training ${ }^{1}$ that consists of repetitive movements, ${ }^{2}{ }^{3}$ pushing anatomical boundaries (eg, turnout, arching) ${ }^{4}$ and demanding versatility (eg, improvisation, inversions). ${ }^{1}$ These demands make a dance student prone to physical health problems, ${ }^{1}$ especially during periods of maturation and development. ${ }^{5} 6$ Physical health problems can lead to discomfort, require medical treatment and inhibit artistic development due to absence from dance activities (ie, classes, rehearsals and performances). ${ }^{1}$ In extreme cases, they can lead to study delay and even dropping out of college. ${ }^{2}$
What are the new findings?

- Contemporary dance students are at high risk for injuries. The 1-year injury incidence proportion (IP) was $81 \%$, of which $58 \%$ were substantially injured. The monthly IP of all injuries ranged from $23 \%$ to $43 \%$ and for substantial injuries from $6 \%$ to $17 \%$.

- The most affected sites were the ankle/foot, lowe back and knee. Injury prevention programmes in dance schools should focus on the prevention of back and lower extremity injuries .

According to Kenny and colleagues, ${ }^{1}$ injury incidence rates ranged from 0.77 to 4.71 per 1000 hours of dance exposure within preprofessional ballet and/or contemporary dancers. ${ }^{1}$ These data resulted from a very broad injury definition ('any physical complaint irrespective of the need for medical attention or full time loss from dance activities'). On the other hand, only reporting time-loss and/or medical attention injuries underestimates the full extent of injury problems. ${ }^{7}$ About $90 \%$ of overuse injuries will not be registered as an injury when focusing on time loss injuries, ${ }^{8}$ whereas the majority of injuries by preprofessional ballet dancers $(54 \%-85 \%)$ appear to be overused in nature. ${ }^{9}$ We argue that injury surveillance methods should use inclusive injury definitions. $^{7}$

In 2013, a new surveillance method was reported by Norwegian clinician-academics. The Oslo Sports Trauma Research Centre (OSTRC) Overuse Injury Questionnaire was designed to address the limitation of injury registration that only counted 'time loss' injuries. ${ }^{8}$ The new method captured all types of health problems-non-time loss injuries ('overuse') and time loss injuries (often 'acute' or more severe overuse injuries). ${ }^{1011}$ Although this method has been used multiple times within athletic groups, ${ }^{12} 13$ only one study has applied this method in dance. ${ }^{7}$ 
Insight into the extent of physical health problems can give direction to future research into the aetiology of injuries and the development of preventive strategies. ${ }^{14}{ }^{15} \mathrm{We}$ aimed to establish the extent (amount, incidence) and characteristics (severity, location) of injuries in contemporary dance students using the OSTRC Overuse Injury Questionnaire. $^{810}$

\section{MATERIALS AND METHODS Participants}

A total of 134 first-year, second-year and third-year contemporary dance students were prospectively followed during the entire academic year (September 2016 to June 2017). Students were enrolled in the 4-year educational programme of Bachelor Dance or Bachelor Dance Teacher of Codarts University of the Arts, Rotterdam, the Netherlands. Our data were routinely collected as part of the curriculum for management and educational purposes. All students were informed about the procedure and provided written informed consent. The study was approved by the Scientific and Ethical Review Board (VCWE) of the Vrije Universiteit Amsterdam. The Dutch Central Committee on Research Involving Human Subjects (CCMO) stated that no medical ethical approval was necessary for this questionnaire study, as stated in the Dutch Medical Research Involving Human Subjects Act (http://www.ccmo.nl/nl/toetsingscommissie-ccmo-ofmetc?55a37b93-dd8c-4bf8-8883-2d30c35ff8ba).

\section{Procedures}

During the first month of the academic year (September 2016), baseline characteristics were recorded, including age (years), height (centimetres) and body weight (kilograms). During the academic year 2016/2017, all students were asked to complete monthly questionnaires by using the Performing Artist and Athletes Health Monitor (PAHM),${ }^{16}$ a web-based system which includes a Dutch translation of the OSTRC Questionnaire on Health Problems. ${ }^{101213}$ Only students who completed $>30 \%$ of the questionnaires were included in the analyses.

\section{Injury registration}

The OSTRC Questionnaire consists of four key questions about the consequences of health problems on participation, training volume and performance as well as the degree to which the student perceived symptoms. All items ranged from 0 (no problem, no reduction, no effect or no symptoms) to 25 (cannot participate at all or severe symptoms). ${ }^{8}$ Questions 1 and 4 were scored on a four point scale (0-8-17-25), while questions 2 and 3 were scored on a five point scale (0-6-13-19-25). The severity of a health problem was calculated by the sum score of the four questions (scale 0-100) according to the method proposed by Clarsen et al. ${ }^{8}$ If the severity score was higher than zero, a health problem was registered and the student was asked whether the health problem was an injury, mental problem or other problem. For injuries, the student was automatically directed to an injury registration form based on an international consensus statement on injury surveillance methodology for football to collect further details (eg, location, history and acute or overuse onset). ${ }^{17}$ An injury was defined as any physical complaint sustained by a dancer resulting in a severity score higher than zero (ie, leading to consequences on participation, training volume and/or performance), irrespective of the need for medical attention or time loss from dance activities.

Students were defined as substantially injured if they reported problems leading to moderate or severe reductions (value $\geq 13$ on question 2 or 3 of the OSTRC) in training volume or moderate or severe reductions in performance or complete inability to participate in dance. ${ }^{10}$ If a student reported the same injury as most severe health problem in two or more consecutive questionnaires, this was counted as one 'unique' case of a (fluctuating) problem. ${ }^{12} 16$

\section{Dance exposure}

Dance exposure was defined as, 'one dancer participating in one class, rehearsal or performance in which he or she is exposed to the possibility of dance injury weighted for time doing activity', ${ }^{18}$ and measured as unit of time (hours) spending on physical dance activities. Total dance exposure was calculated as an average, based on the weekly timetables for the first-year, second-year and third-year students of the educational programme of Bachelor Dance and Bachelor Dance Teacher.

\section{Statistical analysis}

All statistical procedures were performed using SPSS V.23 (IBM, Armonk, USA). Descriptive statistics were used to describe baseline characteristics using means and SD or number and percentages (\%). The (substantial) injury incidence proportion (IP) for one academic year and per month was calculated by dividing the number of students that reported at least one (substantial) injury during the academic year/month by the number of respondents in that same period. ${ }^{19}$ Injury incidence rate, with corresponding $95 \% \mathrm{CI}$, was calculated as the number of unique injuries per 1000 hours of dance exposure. ${ }^{19}$ The severity of the unique injuries was calculated by the mean (SD) number of full days that a student completely/ partly missed their dance activities due to their injury. Characteristics (ie, location) of injuries were expressed in percentages for the total of unique injuries.

\section{RESULTS}

\section{Response and baseline characteristics}

Baseline characteristics of all students are shown in table 1. A total of 137 students were enrolled in the educational programmes, 134 students gave consent to participate and finally 130 students were included in the analyses. The four excluded students all dropped out of the educational programme within 4 months due to personal reasons (no injuries), resulting in a response lower than $30 \%$. In total, 1279 questionnaires were sent 
Table 1 Baseline characteristics shown as mean $( \pm S D)$ or number (percentage)

\begin{tabular}{ll}
\hline & Overall \\
\hline $\mathrm{N}$ & 134 \\
\hline \multicolumn{1}{c}{ Education programme (Bachelor dance) } & $84(62.7 \%)$ \\
\hline First-year students & $49(36.6 \%)$ \\
\hline Second-year students & $44(32.8 \%)$ \\
\hline Third-year students & $41(30.6 \%)$ \\
\hline Gender (female) & $90(67.2 \%)$ \\
Age (years) & $19.4 \pm 1.5$ \\
Body mass index (kg/m $\left.{ }^{2}\right)$ & $21.0 \pm 1.8$ \\
Dance exposure (total hours academic year & 1046.5 \\
2016/2017 per student) & \\
\hline
\end{tabular}

$\mathrm{N}$, number.

to the students and 1020 were completed, resulting in a response rate of $79.7 \%$.

\section{Health problems}

During the academic year, $96.9 \% \quad(n=126)$ of the students reported at least one health problem, of which $64.3 \%$ $(n=81)$ reported a substantial health problem. In the 10 monthly questionnaires, a total of 620 health problems were reported consisting of 321 injuries (51.8\%), 67 mental problems $(10.8 \%)$ and 232 other health problems, including illnesses $(37.4 \%)$.

\section{Injury incidence}

The injury IP for one academic year was $80.8 \%(n=105)$, of which $58.1 \%$ students $(\mathrm{n}=61)$ had a substantial injury. Figure 1 shows that the monthly IP of all injuries ranged from $23.1 \%$ to $42.6 \%$ and from $5.8 \%$ to $16.8 \%$ for substantial injuries. The mean monthly OSTRC severity score for all injuries was $35.3(\mathrm{SD}=5.8)$ and for substantial injuries $57.0(\mathrm{SD}=4.7$; figure 2$)$.

A total of 254 unique injuries were reported by 105 students. Furthermore, 67 subsequent injuries were reported, resulting in a total of 321 reported injuries. The subsequent injuries were reported in at least

\section{Monthly incidence proportion injuries}

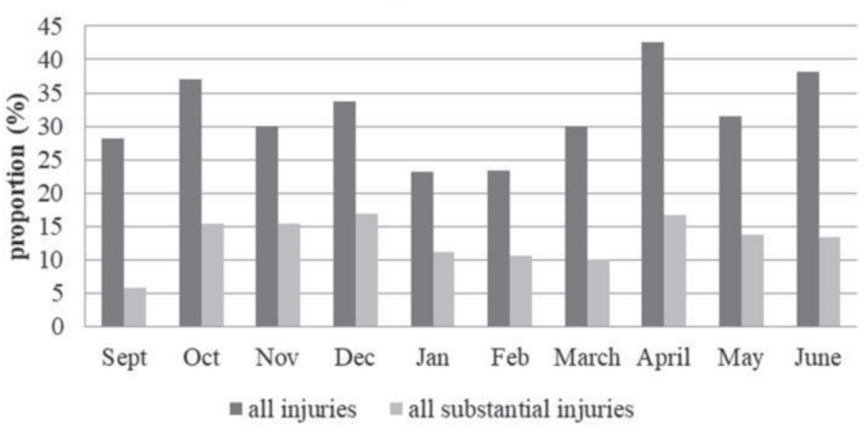

Figure 1 Monthly incidence proportion of all and substantial injuries during the full academic year of 2016/2017.

\section{Monthly OSTRC severity score} injuries

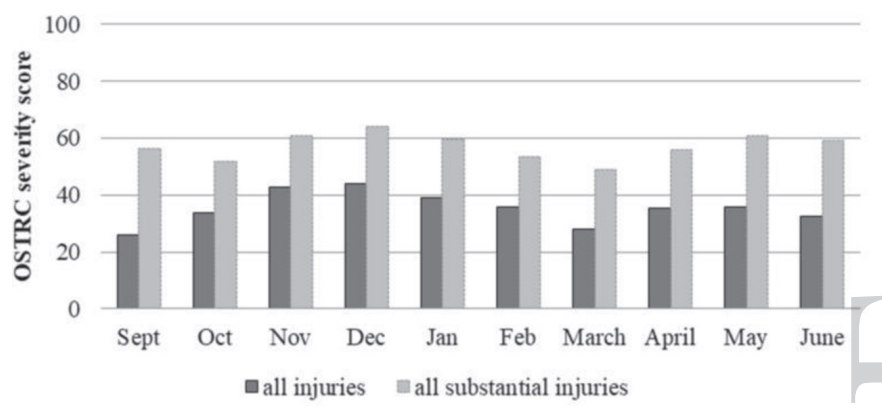

Figure 2 Mean monthly OSTRC severity scores of all and substantial injuries during the full academic year of 2016/2017. OSTRC, Oslo Sports Trauma Research Centre.

two consecutive questionnaires and therefore did not calculate as a unique injury. The 105 students reported on average 2.0 unique injuries (range 1-7) during the academic year. As shown in Figure 3, 25 students (19.2\%) did not report any injuries, 27 students $(20.8 \%)$ reported one unique injury, 36 students $(27.7 \%)$ reported two unique injuries and 42 students $(32.3 \%)$ three or more unique injuries during the academic year.

A total of 132906 dance exposure hours was reported during the academic year, resulting in an overall injury incidence rate of 1.9 unique injuries per 1000 hours (95\% CI 1.7 to 2.2). The mean number of days a student completely/partly missed dance activities as a result of an unique injury was 5.7 days \pm 10.8 ( $\mathrm{n}=252$ students). The most reported anatomical injury locations were ankle/ foot (including ankle, foot/toe, Achilles tendon and heel $(\mathrm{n}=77,30.3 \%))$, lower back (incl. coccyx) $(\mathrm{n}=44,17.3 \%)$ and knee $(\mathrm{n}=37,14.6 \%)$.

\section{DISCUSSION}

Using the PAHM which includes the OSTRC Questionnaire, we found a 1-year injury IP of $81 \%(n=105)$ and an injury incidence rate of 1.9 unique injuries per 1000 hours of dance exposure. Fifty-eight per cent $(n=61)$ of the injured students had a substantial injury, meaning that the students were not able to participate at all or

\section{Injuries per student}

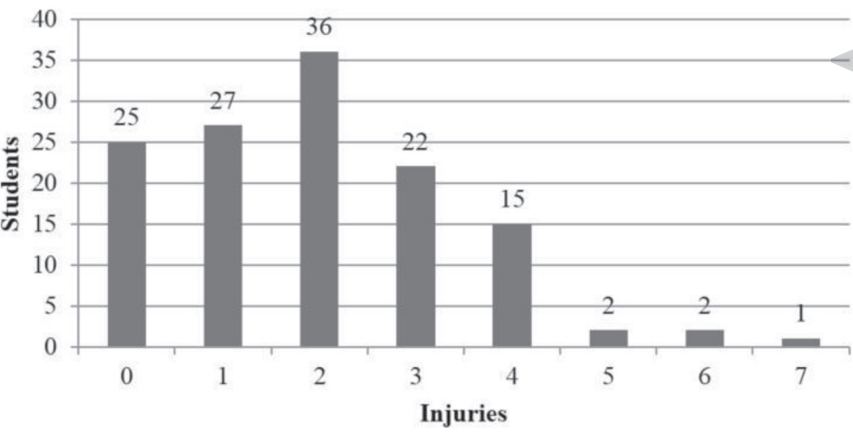

Figure 3 Frequency table of the number of unique injuries per student over the full academic year of 2016/2017. 
had a moderate or severe reduction in training volume or performance because of an injury. The monthly IP for all injuries ranged from $23 \%$ to $43 \%$ and from $6 \%$ to $17 \%$ for substantial injuries. The injured students $(n=105)$ reported on average 2.0 unique injuries (range $1-7$ ). The most reported anatomical injury locations were ankle/ foot, lower back and knee.

\section{Injury incidence and characteristics}

Our findings of the 1-year injury IP of $81 \%$ extend those of other prospective cohort studies within dance. For instance, the study by Lee and colleagues ${ }^{6}$ showed a 1-year IP of $86 \%$ within ballet and contemporary dance students, and Kenny and colleagues ${ }^{7}$ reported a 1-year injury IP of $78 \%$ within contemporary dance students. Moreover, a recent systematic review of Kenny et al indicated an injury IP range from $37 \%$ to $85 \%$ in preprofessional ballet and/or contemporary dancers within 20 follow-up studies, representing controlled trials, cohorts and a case-control research.

The injury incidence rate of the present study of 1.9 per 1000 hours of dance exposure is in contrast to the injury incidence rate of 4.9 per 1000 hours of dance exposure (95\% CI 4.10 to 5.79), reported in the prospective cohort study of Kenny et $a l^{7}{ }^{7}$ The difference may be explained by the different way of calculating the injury incidence rate. Kenny and colleagues used the total number of new injuries to calculate the incidence rate, resulting in the possibility of multiple injuries per week (up to four), whereas this study used the amount of unique injuries over one academic year, with a maximum of one injury (most severe) per month. Selecting all mentioned injuries in our dataset (including multiple injuries per month) led to a great injury incidence rate of 1.9-3.04 per 1000 hours of dance exposure (95\% CI 2.76 to 3.35 ). This higher injury incidence rate is still lower than the injury incidence rate mentioned by Kenny et al. ${ }^{7}$ However, both our injury incidence rates of 1.9 and 3.04 per 1000 hours of dance exposure are in line with the range $(0.77$ 4.71 per 1000 hours of dance exposure) reported in the systematic review of Kenny and colleagues for preprofessional dancers. ${ }^{1}$

Within professional contemporary dancers, a lower injury incidence rate was reported; the study of Shah et $a t^{20}$ indicated a total of 0.59 injuries per 1000 hours, and Bronner et $a l^{21}$ showed 0.51 injuries per 1000 hours. However, these studies did not indicate whether they calculated their exposure rate based on the amount of time each dancer spent on stage or on the length of each show. The difference between dance students and professional dancers might also be attributed to the difference in experience and level. Dance students are still in a period of maturation and development. ${ }^{56}$ In the end, only the fittest (physically and mentally) dancers will remain and become professional dancers. Furthermore, as dancers age and gain experience they are likely to be more aware of the warning signs of injuries and take preventive steps. ${ }^{22}$
To view our results in a wider perspective, we compared the injury incidence rate to other performing/sports populations with the same injury surveillance methodology and age group. The injury incidence rate found in this study is (much) lower than found in circus arts students (3.3 injuries per 1000 hours), ${ }^{16}$ Dutch female gymnasts (5.2 injuries per 1000 hours) ${ }^{13}$ and first-year Physical Education Teacher Education (PETE) students (11.7 injuries per 1000 hours). ${ }^{12}$ The difference might be explained by the differences in demands and environmental factors within these settings compared with our population. For example, PETE students participate in a wide range of different sports (including contact sports like soccer, rugby and so on) which causes them to have an increased risk of various injuries. ${ }^{23}$

In our study, the most predominant injury locations were the ankle/foot (30\%), lower back (15\%) and the knee $(14 \%)$. These results are in line with previous studies; the ankle/foot $(21 \%-34 \%)$, lower back (13\%$17 \%)$ and knee $(12 \%-21 \%) .{ }^{602425}$

\section{Strengths, limitations and recommendations}

A major strength of this study is the prospective design with monthly follow-up, resulting in a low potential for recall bias. Besides, the response rate to the monthly questionnaire was high $(80 \%)$. This was achieved by incorporating the monitor as part of the educational programme. As recommended by Richardson and colleagues, ${ }^{13}$ an online feedback tool (PAHM) ${ }^{16}$ was used to give students visual feedback of the collected data to improve their commitment to this study. Furthermore, students were involved in the development of PAHM, by incorporating their feedback in the new versions of PAHM.

Another major strength of this study is the use of a broad injury definition and the surveillance method as suggested by Clarsen and colleagues to calculate the extent of injuries within contemporary dance students. ${ }^{810}$ The incidence and severity of injuries impacting dance students vary depending on the definition of injury and injury reporting methodology. ${ }^{7}$ Therefore, to understand the full impact of injuries on a dance population, it is imperative that injury surveillance systems consider injury definitions that are sensitive enough to capture all injuries, ${ }^{7}$ such as used in this study.

However, there are some limitations. First of all, in this study, we used student-reported outcomes. Since most students lack medical expertise we were unable to record specific diagnoses of the reported injuries. It is recommended to include a follow-up from the medical staff during the data collection period in future studies, to gain more insight into the injury type and aetiology.

Furthermore, although our study indicated exposure by measuring the hours of dance classes, the intensity and nature of these classes were not included in the exposure analysis. However, these factors may have an impact on the potential injury risk for individual dancers. ${ }^{625} \mathrm{In}$ this study, dance exposure was calculated from the basic 
timetable for each year and educational programme but not individually and therefore may not truly reflect the actual hours of training or engagement by each individual student. Non-scheduled dance practice, additional workouts and performances were not included in the total number of hours of dance exposure. Future research should look more closely at the number of and rapid changes in training load, which can precede the onset of injury. ${ }^{626}$ Besides, it is necessary to gain insight into the variance within the monthly IPs of injuries in relation to the curriculum of the two educational programmes, to optimise the training load over the full academic year.

Acknowledgements The authors would like to thank Suze Steemers, Annemiek Tiemens and Stephanie Keizer-Hulsebosch for their help in administrating the monthly questionnaires and their help during the physical performance tests.

Contributors All authors made a substantial contribution to the information and material submitted and have read and approved the final version. DVW performed the data collection analysed the data and wrote the manuscript. RMVR assisted with performing the data collection, analysing the data and writing the manuscript. AR assisted with the data analyses. GJPS, RRD0 and JS initiated the study and contributed to the content of the article.

Funding This work was supported by the National association of Applied Sciences SIA under Grant number 2015-02-73P.

Disclaimer The authors report no financial interest or benefit arising from the direct applications of this research.

Competing interests None declared.

Patient consent for publication Not required

Provenance and peer review Not commissioned; externally peer reviewed.

Open access This is an open access article distributed in accordance with the Creative Commons Attribution Non Commercial (CC BY-NC 4.0) license, which permits others to distribute, remix, adapt, build upon this work non-commercially, and license their derivative works on different terms, provided the original work is properly cited, appropriate credit is given, any changes made indicated, and the use is non-commercial. See: http://creativecommons.org/licenses/by-nc/4.0/.

\section{REFERENCES}

1. Kenny SJ, Whittaker JL, Emery CA. Risk factors for musculoskeletal injury in preprofessional dancers: a systematic review. Br J Sports Med 2016;50:997-1003.

2. Ekegren CL, Quested R, Brodrick A. Injuries in pre-professional ballet dancers: incidence, characteristics and consequences. J Sci Med Sport 2014;17:271-5.

3. Gamboa JM, Roberts LA, Maring J, et al. Injury patterns in elite preprofessional ballet dancers and the utility of screening programs to identify risk characteristics. J Orthop Sports Phys Ther 2008;38:126-36.

4. Luke AC, Kinney SA, Hemecourt PAD, et al. Determinants of injuries in young dancers. Med Probl Perform Art 2002;17:105-12.

5. Bowerman $\mathrm{E}$, Whatman $\mathrm{C}$, Harris N, et al. Are maturation, growth and lower extremity alignment associated with overuse injury in elite adolescent ballet dancers? Phys Ther Sport 2014;15:234-41.
6. Lee L, Reid D, Cadwell J, et al. Injury incidence, dance exposure and the use of the movement competency screen (MCS) to identify variables associated with injury in full-time Pre-Professional dancers. Int J Sports Phys Ther 2017;12:352-70.

7. Kenny SJ, Palacios-Derflingher L, Whittaker JL, et al. The influence of injury definition on injury burden in preprofessional ballet and contemporary dancers. J Orthop Sports Phys Ther 2018;48:185-93.

8. Clarsen B, Myklebust G, Bahr R. Development and validation of a new method for the registration of overuse injuries in sports injury epidemiology: the Oslo sports trauma research centre (OSTRC) overuse injury questionnaire. Br J Sports Med 2013;47:495-502.

9. Caine D, Goodwin BJ, Caine CG, et al. Epidemiological review of injury in Pre-Professional ballet dancers. J Dance Med Sci 2015;19:140-8.

10. Clarsen B, Rønsen O, Myklebust G, et al. The Oslo sports trauma research center questionnaire on health problems: a new approach to prospective monitoring of illness and injury in elite athletes. $\mathrm{Br} \mathrm{J}$ Sports Med 2014;48:754-60.

11. Pluim BM, Loeffen FGJ, Clarsen B, et al. A one-season prospective study of injuries and illness in elite junior tennis. Scand J Med Sci Sports 2016;26:564-71.

12. van Beijsterveldt AM, Richardson A, Clarsen B, et al. Sports injuries and illnesses in first-year physical education teacher education students. BMJ Open Sport Exerc Med 2017;3:e000189.

13. Richardson A, Clarsen B, Verhagen E, et al. High prevalence of selfreported injuries and illnesses in talented female athletes. BMJ Open Sport Exerc Med 2017;3:e000199.

14. Finch C. A new framework for research leading to sports injury prevention. J Sci Med Sport 2006;9:3-9.

15. van Mechelen W, Hlobil H, Incidence KHCG. Severity, aetiology and prevention of sports injuries: a review of concepts. Sport Med 1992;14:82-99.

16. Stubbe JH, Richardson A, van Rijn RM. Prospective cohort study on Injuries and health problems among Circus arts students. BMJ Open Sport Exerc Med 2018;4:e000327.

17. Fuller CW, Ekstrand J, Junge A, et al. Consensus statement on injury definitions and data collection procedures in studies of football (soccer) injuries. Scand J Med Sci Sports 2006;16:83-92.

18. Liederbach M, Hagins M, Gamboa JM, et al. Assessing and reporting dancer capacities, risk factors, and injuries: recommendations from the IADMS standard measures consensus initiative. J Danc Med Sci 2012;16:139-53.

19. Knowles SB, Marshall SW, Guskiewicz KM. Issues in estimating risks and rates in sports injury research. $J$ Athl Train 2006;41:207-15.

20. Shah S, Weiss DS, Burchette RJ. Injuries in professional modern dancers: incidence, risk factors, and management. J Danc Med Sci 2012;16:17-25.

21. Bronner S, Ojofeitimi S, Rose D. Injuries in a modern dance company. Am J Sports Med 2003;31:365-73.

22. Thomas H, Tarr J. Dancers' Perceptions of Pain and Injury: Positive and Negative Effects. J Danc Med Sci 2009;13:51-9.

23. Goossens L, Cardon G, Witvrouw E, et al. A multifactorial injury prevention intervention reduces injury incidence in physical education teacher education students. Eur J Sport Sci 2016;16:365-73.

24. Baker J, Scott D, Watkins K, et al. Self-reported and reported Injury patterns in contemporary dance students. Med Probl Perform Art 2010;25:10-15.

25. Campoy FA, Coelho LR, Bastos FN, et al. Investigation of risk factors and characteristics of dance injuries. Clin J Sport Med 2011;21:493-8.

26. Drew M. Managing load or managing risk. Sport Physio 2015;2. 